\title{
Polyacrylamide Gel Electrophoresis of Proteins Method versus Enzyme-Linked Immunosorbent Assay and Immunochromatography with Monoclonal Antibodies in Pediatric Infection with Helicobacter Pylori
}

\author{
RALUCA SUZANA IFTIMI ${ }^{1}$, ANA MARIA ALEXANDRA STANESCU ${ }^{2}$, \\ CARMEN ANTON ${ }^{3 *}$, SMARANDA DIACONESCU ${ }^{1,3 *}$, NICOLETA GIMIGA ${ }^{1,3}$, \\ OANA-MARIA ROSU ${ }^{4}$ \\ ${ }^{1}$ St. Mary Clinical Emergency Hospital for Children, 62 Vasile Lupu Str., 700309, Iasi, Romania \\ ${ }^{2}$ Carol Davila University of Medicine and Pharmacy, 8 Eroii Sanitari Str., 050474, Bucharest, Romania \\ ${ }^{3}$ Gr. T. Popa University of Medicine and Pharmacy, 16 Universitatii Str., 700115, Iasi, Romania \\ ${ }^{4}$ University of Medicine, Parmacy, Science and Technology, 38 Gh. Marinescu Str., 540072, Targu Mures, Romania
}

\begin{abstract}
The current methods for the diagnosis of Helicobacter pylori infection in children include invasive (direct) methods, that enable the detection of the bacteria or the bacterial urease in gastric biopsies, or noninvasive (indirect) methods, which consist of researching specific antibodies, antigens and urease in other different samples (serum, saliva, urine, stool, exhaled air). The urease functions in H. pylori infection is to neutralize gastric acid by producing NH3 through the hydrolysis of urea. Monochloramine, a NH3-derived compounds has cytotoxic effects on host cells. The Western Blot method refers to the extraction of a a sodium dodecyl sulphate from a Helicobacter pylori strain followed by a separation of the solubilised protein using discontinous polyacrylamide gel electrophoresis according to molecular mass and transfer of the separated proteins to nitrocellulose. The ELISA (enzyme-linked immunosorbent assay) technique refers to the detection of AntiHelicobacter pylori antibodies type Ig G. We also used an immunochromatographic system with the lateral leakage test strip based on the principle of the sandwich technique with monoclonal antibodies. As a result, more than two types of reactions can be detected on a single assay device by the combination of colloidal gold-labelled antibodies and complementary oligonucleotide-labelled immobilized at different places on a nitrocellulose membrane. Our study aims to assess the performances of the Western Blot method for determining anti-Helicobacter pylori Ig A and Ig $G$ antibodies in correlation with clinical data and other available diagnosis methods. For validation purposes, the results were compared to those obtained using the enzyme-linked immunosorbent assay technique, gastric biopsy and immunochromatography.
\end{abstract}

Keywords: Helicobacter pylori, Western Blot, ELISA, biopsy, children

\section{Introduction}

The fundamental research in the pediatric infection with Helicobacter pylori gather clinical aspects with endoscopic and immunological aspects.

According to ESPGHAN guidelines (2016), the diagnosis of Helicobacter pylori infection in children is made based on the following recommendations:

- The initial diagnosis of Helicobacter pylori infection is based on a positive histopathology, a positive rapid urease test or a positive culture;

- Stool antigen testing for Helicobacter pylori is a non-invasive test that is not recommended for the initial diagnosis of the infection in children;

*email: carmen_ro2008@yahoo.com,turti23@yahoo.com 
- Serum or whole blood anti-Helicobacter pylori (Ig G, Ig A) antibody tests are not reliable for use in clinical conditions;

- It is recommended to test Helicobacter pylori using stool samples or using a biopsy at least 2 weeks after stopping proton pump inhibitor (PPI) therapy and minimum 4 weeks after stopping the antibiotic treatment;

- Diagnosis tests for the Helicobacter pylori infection are not recommended to children with functional abdominal pain. (1)

With the exception of molecular biology techniques that are available only in research laboratories, all these methods can be used for current diagnosis.

The role of serological testing was limited owing to cross-reactivity with antibodies against other bacterial species which may lead to false-positive reactions. Also, high titers that can persist up to 4-6 months (sometimes even up to several years) after eradicating the infection may lead to false-positive reactions. False-negative results may occur in the early stages of the infection (serum IgG are detectable in approximately 20 days after the infection, depending on the patient). (4) Stool antigen detection using rapid qualitative tests is an efficient method that indicates a current infection, the occurrence of a reinfection and monitoring treatment effectiveness, but it has the disadvantage of low reproducibility; the method is acceptable for adult patients. $(2,3)$

The profile of serum antibodies compared to different antigens of the Helicobacter pylori bacterium can be monitored using the (Immunoblot Test). This is a quantitative, non-invasive method allowing the simultaneous study of antibodies against several antigen fractions. It is a well-known fact that less than $2 \%$ of infected patients present with seroconversion, therefore an optimal and sensitive Western Blot system should be able to detect approximately $98 \%$ of active infections. (5)

The largest part of enzyme linked immunoabsorbed assays (the ELISA technique) is based on the detection of anti-Helicobacter pylori antibodies type IgG. Such preparations include antigens that may have cross-reactions with other bacterial species, resulting in a specificity that rarely exceeds $90 \%$. Even $4^{\text {th }}$ generation ELISA systems that contain highly purified substances still entail a risk for crossreactions. (4)

The Western Blot technique allows for direct visualization of antibodies binding to specific antigens. Compared to the ELISA technique, this method is more cost and labor-intensive, but it has the advantage of accurately characterizing the humoral immune response to different types of bacterial virulence antigens. This method is also used to confirm positive and equivocal results obtained using another technique. (5)

Western Blot helps detect both recurrent an ongoing Helicobacter pylori infections. Results are correlated with those of invasive tests. The kit contains the ready-to-use test strips, the control matrix (Figure 1), enzyme conjugate, universal buffer, and sublayer solution. Kits provide a qualitative "in vitro" test to determine IgA and IgG class antibodies, and a quantitative test for the bacterial virulence antigens included on the strip They contain ready-to-use strips with electrophoretically separated Helicobacter pylori antigens. The proteins in polyacrylamide gels interact with antibodies, and the membranes used for blotting are made of nitrocellulose.

There are 2 phases identified in this technique: during the first phase proteins are separated and blocked, and during the second phase the immobilized protein can interact with the antibody. The binding of specific antibodies occurs after incubation with enzyme conjugate, which contains alkaline phosphatase. The complex is identified following an enzymatic reaction that will generate colored reaction product, the intensity of which shall be measured. After carrying out the work procedure, after the blot strips are dried, they were scanned using a densitometric scanner and analyzed using a specialized program for the analysis of dimensional separations - EUROLine Scan. (Figures 2, 3) 


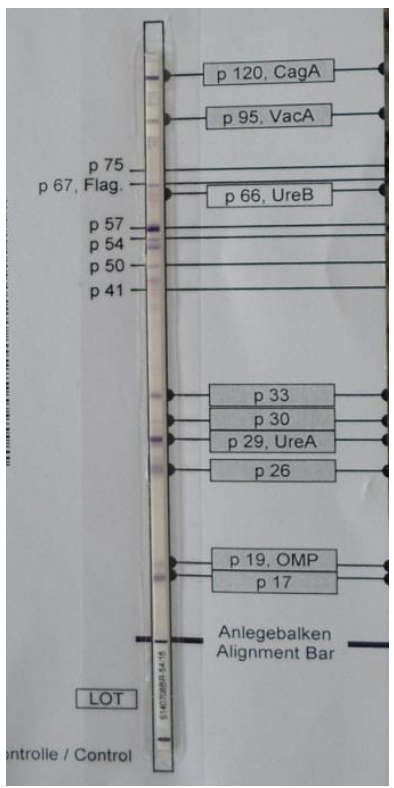

Figure 1. Anti-Helicobacter pylori Euroline Western Blot control matrix

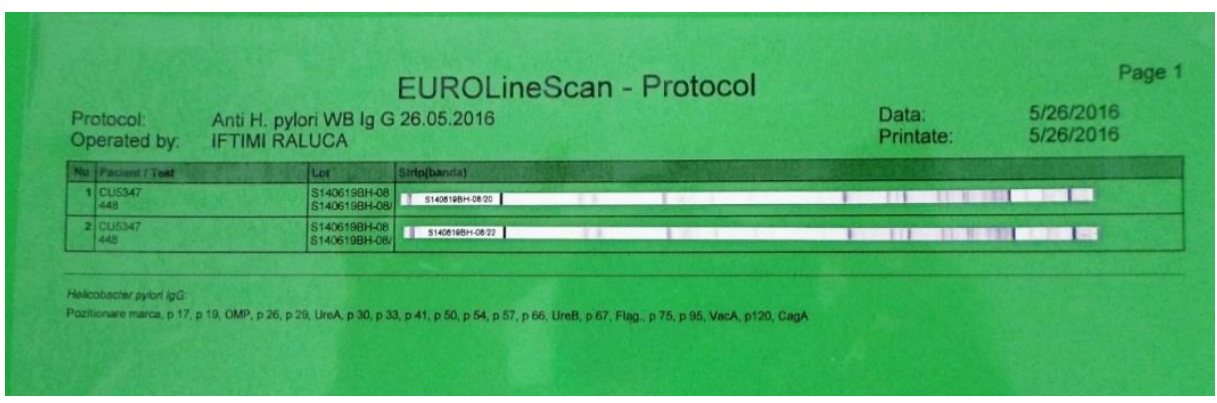

Figure 2. Helicobacter pylori IgG Western Blot workflow model

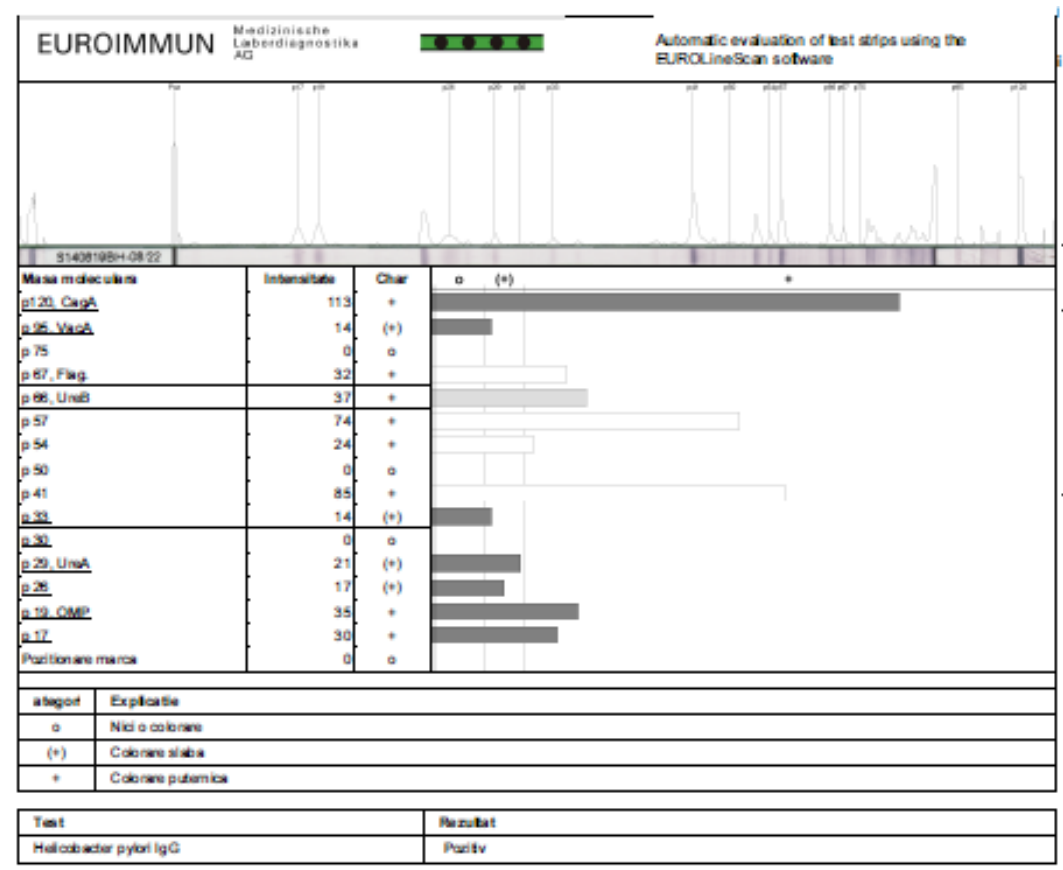

Figure 3. EUROLineScan strip analysis model

The specificity of antigens included on the strip is presented in Table 1. 
Table 1. Specificity of antigens included on the strip:

\begin{tabular}{|c|c|}
\hline Antigen & Specificity \\
\hline Cag A-p120 & Cytotoxin-associated gene A - High specificity \\
\hline Vac A-p95 & Vacuolating cytotoxin gene A - High specificity \\
\hline p75 & Nonspecific \\
\hline FSH, p67 & Flagellar sheath protein - Nonspecific due to cross-reactivity with another bacterium \\
\hline UreB- p66 & Urease heavy subunit - Cross-reactivity with another bacterium containing urease \\
\hline HSP, p57 & Nonspecific \\
\hline Flagellin & Nonspecific due to cross-reactivity with another bacterium having flagella \\
\hline p50 & Nonspecific \\
\hline p41 & Nonspecific \\
\hline p33 & Probably specific \\
\hline OMP-p30 & Outer membrane protein - Species specificity \\
\hline UreA-p29 & Urease light subunit - High specificity \\
\hline p26 & High specificity \\
\hline OMP- p19 & Species specificity \\
\hline p17 & Probably specific \\
\hline
\end{tabular}

Helicobacter pylori antigens were divided into three categories:

Class 1: nonspecific antigens that have cross-reactivity, with a molecular weight of $41 \mathrm{kDa}(\mathrm{p} 41)$, $50 \mathrm{kDa}$ (p50), $54 \mathrm{kDa}$ (flagellin), $57 \mathrm{kDa}$ (HSP), $67 \mathrm{kDa}$ (FSH) and $75 \mathrm{kDa}(\mathrm{p} 75)$.

Class 2: antigens with a molecular weight of $66 \mathrm{kDa}$ (urease $\mathrm{B}$ )

Class 3: antigens with species specificity and high specificity with a molecular weight of $17 \mathrm{kDa}$ (p17), 19 kDa (OMP), 26 kDa (p26), 29 kDa (urease A), 30 kDa (OMP), 33 kDa (p33), 95 kDa (Vac A) and $120 \mathrm{kDa}(\mathrm{Cag} \mathrm{A})$.

\section{Materials and methods}

The two-year study included 73 patients, with ages between 2 and 17 years old, admitted to the Gastroenterology Department at the "Sf. Maria" Clinical Emergency Children's Hospital in Iași, who underwent upper gastrointestinal endoscopy for the accepted indications. The primary selection criterion was gastric biopsy positivity, with a microscopic smear test and rapid urease test for Helicobacter pylori. Another inclusion criterion was the absence of a recent treatment with antibiotics or proton pump inhibitors. Exclusion criteria: patients with negative gastric biopsy for Helicobacter pylori, patients whose biopsy samples were improperly collected, and lack of informed consent.

Up to four fragments of gastric biopsy and venous blood samples were collected from all the patients. Serums were collected after clotting of the blood, separated after centrifugation, and stored at $-20^{\circ} \mathrm{C}$.

The serums were then examined based on the Western Blot technique using the Helicobacter pylori IgA Western Blot and Helicobacter pylori IgG Western Blot kits in accordance with the manufacturer's protocol, i.e. Euroimmun Labordiagnostika ${ }^{\circledR}$ (Germany).

The Western Blot test results were divided into 3 categories: negative, uncertain and positive, as presented in Table 2.

Table 2. Interpretation of results for Helicobacter pylori IgA Western Blot and Helicobacter pylori IgG Western Blot

\begin{tabular}{|c|c|}
\hline Result & Characteristics \\
\hline Negative & $\begin{array}{l}\text { No antigen bands recognisable or some weak antigen bands of categories } 1 \text { and } 2 \text { or one single weak antigen band } \\
\text { from category } 3\end{array}$ \\
\hline \multirow[t]{2}{*}{ Borderline } & $\begin{array}{c}\text { A minimum of two weak antigen bands from categories } 2 \text { or } 3 \text { or one distinctive antigen band from category 3- } \\
\text { Helicobacter pylori IgA Western Blot }\end{array}$ \\
\hline & $\begin{array}{c}\text { A distinctive antigen band from category } 3 \text { or a minimum of two weak antigen bands from category } 3-\text { Helicobacter } \\
\text { pylori IgG Western Blot }\end{array}$ \\
\hline \multirow[t]{2}{*}{ Positive } & A minimum of two distinctive antigen bands from categories 2 or $3-$ Helicobacter pylori IgA Western Blot \\
\hline & A minimum of two distinctive antigen bands from category 3 - Helicobacter pylori IgG Western Blot \\
\hline
\end{tabular}


The results obtained using the Western Blot technique were compared to those obtained using the ELISA technique for determining anti-Helicobacter pylori IgG antibodies (kit by Euroimmun Labordiagnostika ${ }^{\circledR}$, Germany), as well as to those obtained via invasive methods (gastric biopsy). The study was approved by the Ethic Commission of our hospital (no. 5033/24.02.2016)

\section{Results and discussions}

The age distribution of children in the study sample was as follows: $4.11 \%$ cases aged 2 to 5 years old, $15.07 \%$ cases aged 6 to 10 years old, and $80.82 \%$ cases aged 11 to 17 years old (Table 3 ).

Table 3. Distribution of patients infected with Helicobacter pylori by age groups

\begin{tabular}{|c|c|c|c|c|c|}
\hline Age & No. of cases & $\mathbf{\%}$ & Age & No. of cases & \% \\
\hline 2 years & 1 & 1.37 & 11 years & 5 & 6.85 \\
\hline 3 years & 1 & 1.37 & 12 years & 4 & 5.48 \\
\hline 5 years & 1 & 1.37 & 13 years & 6 & 8.22 \\
\hline 6 years & 2 & 2.74 & 14 years & 7 & 9.59 \\
\hline 7 years & 3 & 4.11 & 15 years & 10 & 13.70 \\
\hline 8 years & 1 & 1.37 & 16 years & 11 & 15.07 \\
\hline 9 years & 2 & 2.74 & 17 years & 16 & 21.92 \\
\hline 10 years & 3 & 4.11 & & & \\
\hline Total & $\mathbf{1 4}$ & $\mathbf{1 9 . 1 8 \%}$ & Total & $\mathbf{5 9}$ & $\mathbf{8 0 . 8 2 \%}$ \\
\hline
\end{tabular}

The distribution of patients infected with Helicobacter pylori according to gender indicated a $34.25 \%$ frequency in male patients and a $65.75 \%$ frequency in female patients (Table 4 ).

Table 4. Distribution of patients infected with Helicobacter pylori, by gender

\begin{tabular}{|l|l|l|}
\hline Patient's sex & No. of cases & \% \\
\hline Female & 48 & 65.75 \\
\hline Male & 25 & 34.25 \\
\hline TOTAL & 73 & 100.00 \\
\hline
\end{tabular}

Patients with rapid urease test and microscopic test directly positive for Helicobacter pylori in fragments of gastric biopsy had endoscopic modifications for gastritis at a rate of $91.78 \%(58.97 \%$ nodular gastritis, $19.58 \%$ erythematous gastritis and $13.23 \%$ hemorrhagic gastritis), $68.49 \%$ for duodenitis, $41.10 \%$ for esophagitis, and $26.03 \%$ for duodenal-gastric reflux. We registered 3 cases of duodenal ulcer and 2 cases of gastric ulcer. (Table 5)

Table 5. Endoscopic modifications in the sample patients:

\begin{tabular}{|l|l|l|}
\hline ENDOSCOPIC FINDINGS & No. of cases & \% \\
\hline ESOPHAGITIS & 30 & 41.10 \\
\hline GASTRITIS & 67 & 91.78 \\
\hline GASTRIC POLYP & 1 & 1.37 \\
\hline HIATAL HERNIA & 1 & 1.37 \\
\hline DUODENAL ULCER & 3 & 4.11 \\
\hline GASTRIC ULCER & 2 & 2.74 \\
\hline DUODENAL-GASTRIC REFLUX & 19 & 26.03 \\
\hline DUODENITIS & 50 & 68.49 \\
\hline
\end{tabular}

Based on the analysis of results obtained using the Western Blot technique on the serums from patients with Helicobacter pylori infection diagnosed via invasive methods, depending on the intensity of identifiable antigen strips and classification thereof in the three classes (positive, uncertain and 
negative) for determining the presence or absence of $\operatorname{IgA}$ and $\operatorname{IgG}$ class antibodies we recorded the following: (Table 6)

- $36.99 \%$ positive results for anti-Helicobacter pylori IgA antibodies and 58.90\% positive antiHelicobacter pylori IgG;

- 54.79\% negative anti-Helicobacter pylori IgA Western Blot and $28.77 \%$ negative antiHelicobacter pylori IgG Western Blot

Table 6. Western Blot test performances in patients included in the study

\begin{tabular}{|c|c|c|c|}
\hline \multicolumn{3}{|c|}{ Biopsy patients } & No. of cases \\
\hline 1 & Anti-Helicobacter pylori IgA Western Blot & 27 & 36.99 \\
\hline 2 & POSITIVE & 40 & 54.79 \\
\hline 3 & NEGATIVE & 6 & 8.22 \\
\hline & UNCLEAR & 73 & $\%$ \\
\hline & TOTAL & No. of cases & 58.90 \\
\hline 1 & Anti-Helicobacter pylori IgG Western Blot & 43 & 28.77 \\
\hline 2 & POSITIVE & 21 & 12.33 \\
\hline 3 & NEGATIVE & 9 & \\
\hline
\end{tabular}

Analyzing the correlations between Ig A and Ig G Western Blot results and the endoscopic aspects we recorded a ratio of $39.13 \%$ positive $\operatorname{IgA}$ results and $62.32 \%$ positive $\operatorname{IgG}$ results in patients with gastritis, $40.38 \%$ positive $\mathrm{IgA}$ results and $67.31 \%$ positive $\mathrm{IgG}$ results in patients with duodenitis, $48.39 \%$ positive IgA results and $61.29 \%$ positive IgG results in patients with esophagitis. (Table 7 ) In patients with gastric ulcer and duodenal ulcer we recorded $100 \%$ positive $\operatorname{IgA}$ and IgG results. We noted that the positivity rate of Helicobacter pylori IgG Western Blot correlated to a larger extent with the endoscopic aspects compared to Helicobacter pylori IgA Western Blot.

Table 7. Correlations between IgA and IgG Western Blot and endoscopic aspects:

\begin{tabular}{|c|c|c|c|c|c|c|c|}
\hline \multicolumn{2}{|c|}{} & \multicolumn{2}{c|}{ Esophagitis } & \multicolumn{2}{c|}{ Gastritis } & \multicolumn{2}{c|}{ Duodenitis } \\
\hline & $\begin{array}{c}\text { Anti-Helicobacter pylori IgA } \\
\text { Western Blot }\end{array}$ & No. of cases & $\%$ & No. of cases & $\%$ & No. of cases & $\%$ \\
\hline 1 & POSITIVE & 15 & 48.39 & 21 & 39,13 & 20 & 40.38 \\
\hline 2 & NEGATIVE & 13 & 45.16 & 37 & 55,07 & 27 & 53.85 \\
\hline 3 & UNCLEAR & 2 & 6.45 & 4 & 5,8 & 3 & 5.77 \\
\hline & TOTAL & 30 & & 67 & & 50 & \\
\hline & & & & & & & \\
\hline & Anti-Helicobacter pylori IgG & No. of cases & $\%$ & No. of cases & $\%$ & No. of cases & $\%$ \\
\hline 1 & Western Blot & 18 & 61.29 & 42 & 62,32 & 34 & 67.31 \\
\hline 2 & POSITIVE & 8 & 25.81 & 18 & 27,54 & 10 & 21.15 \\
\hline 3 & NEGATIVE & 4 & 12.9 & 7 & 10,14 & 6 & 11.54 \\
\hline & UNCLEAR & 30 & & 67 & & 50 & \multirow{2}{*}{ \% } \\
\hline
\end{tabular}

We analysed the results anti-Helicobacter pylori IgG antibodies identified using the ELISA technique. Of the 73 patients included in the study, with positive biopsy, 66 (90.4\%) had positive titer 
for anti-Helicobacter pylori IgG antibodies, 6 (8.2\%) had negative results for anti-Helicobacter pylori $\mathrm{IgG}$ antibodies, and there was 1 equivocal result (1.36\%). The gastric biopsy results correlate at a rate of $90.4 \%$ with the titer for anti-Helicobacter pylori IgG antibodies obtained using the ELISA technique. The confirmation of these results and elimination of false-positive results is carried out using the Western Blot technique (elimination of cross-reactivity).

The results obtained using the Western Blot technique and those obtained using the ELISA technique were compared in Table 8.

Table 8. Correspondence between the results obtained using the Western Blot technique and those obtained using the ELISA technique

\begin{tabular}{|c|c|c|c|c|c|c|c|c|c|c|c|}
\hline \multicolumn{6}{|c|}{ Anti-Helicobacter pylori IgA Western Blot } & \multicolumn{6}{|c|}{ Anti-Helicobacter pylori IgG antibody ELISA RU/ ml } \\
\hline \multicolumn{2}{|c|}{ Positive result } & \multicolumn{2}{|c|}{ Negative result } & \multicolumn{2}{|c|}{ Unclear result } & \multicolumn{2}{|c|}{$\begin{array}{c}\text { Negative result: } \\
<16\end{array}$} & \multicolumn{2}{|c|}{$\begin{array}{c}\text { Equivocal result: } \\
16-22\end{array}$} & \multicolumn{2}{|c|}{ Positive result: $>22$} \\
\hline No. & $\%$ & No. & $\%$ & No. & $\%$ & No. & $\%$ & No. & $\%$ & No. & $\%$ \\
\hline 27 & 36.99 & & & & & 2 & 7.4 & 0 & 0 & 25 & 92.5 \\
\hline & & 40 & 54.79 & & & 3 & 7.5 & 1 & 2.5 & 36 & 90 \\
\hline & & & & 6 & 8.22 & 1 & 16.6 & 0 & 0 & 5 & 83.3 \\
\hline \multicolumn{12}{|c|}{ Anti-Helicobacter pylori IgG Western Blot } \\
\hline 43 & 58.90 & & & & & 2 & 4.65 & 1 & 2.32 & 40 & 93.02 \\
\hline & & 21 & 28.77 & & & 3 & 14.2 & 0 & 0 & 18 & 85.7 \\
\hline & & & & 9 & 12.33 & 1 & 11.1 & 0 & 0 & 8 & 88.8 \\
\hline
\end{tabular}

Twenty-seven patients (36.99\%) positive for anti-Helicobacter pylori IgA Western Blot had 7.4\% negative and $92.5 \%$ positive result for anti-Helicobacter pylori IgG antibodies via the ELISA technique. Fourty-three patients $(58.90 \%)$ positive for anti-Helicobacter pylori IgG Western Blot had 4.65\% negative and $93.02 \%$ positive result for anti-Helicobacter pylori IgG antibodies via the ELISA technique. The fourty patients with negative anti-Helicobacter pylori IgA Western Blot had 90\% positive and $7.5 \%$ negative result for anti-Helicobacter pylori IgG antibodies via the ELISA technique.

The 21 patients with negative anti-Helicobacter pylori IgG Western Blot had $85.7 \%$ positive and $14.2 \%$ negative result for anti-Helicobacter pylori IgG antibodies via the ELISA technique.

For a part of the study group we used immunochromatography to determine the presence of Helicobacter pylori stool antigen. Of the 20 patients that were tested, only one returned a positive result, which was unconfirmed via the Western Blot technique (Table 9).

Table 9. Correspondence between the results obtained using the Western Blot technique and those obtained via immunochromatography (stool antigen)

\begin{tabular}{|l|c|c|c|}
\hline & $\begin{array}{c}\text { Helicobacter pylori } \\
\text { IgA Western Blot }\end{array}$ & $\begin{array}{c}\text { Helicobacter pylori } \\
\text { IgG Western Blot }\end{array}$ & $\begin{array}{c}\text { Helicobacter pylori } \\
\text { Antigen }\end{array}$ \\
\hline 1 & Negative & Negative & Negative \\
\hline 2 & Negative & Positive & Negative \\
\hline 3 & Negative & Positive & Negative \\
\hline 4 & Negative & Positive & Negative \\
\hline 5 & Negative & Positive & Negative \\
\hline 6 & Positive & Unclear & Negative \\
\hline 7 & Negative & Positive & Negative \\
\hline 8 & Negative & Negative & Negative \\
\hline 9 & Negative & Positive & Negative \\
\hline 10 & Negative & Positive & Negative \\
\hline 11 & Positive & Positive & Negative \\
\hline 12 & Positive & Positive & Negative \\
\hline 13 & Negative & Positive & Negative \\
\hline 14 & Negative & Positive & Negative \\
\hline 15 & Negative & Negative & Positive \\
\hline 16 & Negative & Unclear & Negative \\
\hline 17 & Negative & Negative & Negative \\
\hline 18 & Negative & Positive & Negative \\
\hline 19 & Negative & Negative & \\
\hline 20 & Negative & & \\
\hline
\end{tabular}


In the study group we noticed a statistically significant increase of Helicobacter pylori infection cases with age, $\left(p=0.00042, \chi^{2}=15.92\right)$. Comparing the 2 to 10 years old and 11 to 17 years old age groups, we obtained the value $\mathrm{p}=0.0000533(<0.01)$, respectively pyates $=0.0000639$ which reflects a significant difference $(R R=0.14$ in the group 2-10 years compared to $R R=0.72$ in the group 11-17 years), children aged $>11$ years old being more affected.

In our study we noticed that older patients had a higher number of immunoreactive strips than younger ones. Hunt et al. report that the prevalence of Helicobacter pylori infection in Ethiopian children aged 2 to 4 years old was 48\%, while in adults it exceeded 95\%; in Nigeria, the prevalence of the infection in children aged 5 to 9 years old was $82 \%$, while in adults it ranged between 70 to $90 \%$ and similar data was reported in Mexico. Percentages are lower in developed countries. In Canada, children aged 5 to 18 years old had a $7.1 \%$ recorded prevalence of infection, while the percentage recorded for adults was of $23.1 \%$. In Europe, the highest prevalence of infection was found in children in Bulgaria (61.7\%), while the lowest number of infected children were from the Netherlands (1.2\%). (6)

We also note a similar distribution of positive cases according to gender $\left(p=0.427, \chi^{2}=0.22\right.$, $p_{Y a t e s}=0.483$ ). We can state that there is no statistically significant correlation between the presence of infection and patients' sex. This data is consistent with those reported by other authors. A study conducted on 487 patients showed that the incidence of H.pylori infection was higher in women than in men $(38.7 \%$ compared to $34.1 \%)$; however, the difference was not statistically significant $(\mathrm{p}=0.301) .(7)$

Using the Mann-Whitney U statistical test, we note that the degree of positivity for Helicobacter pylori IgG Western Blot is correlated in a higher percentage with the positive biopsy compared to Helicobacter pylori IgA Western Blot. The Z-Score is 5.71233 and the p-value is 0.0027 for Ig A, and the the Z-Score is 2.99804 , the p-value is $<0.00001$ for IgG.

Gastric biopsy results correlate at a rate of $90.4 \%$ with the titer for anti-Helicobacter pylori IgG antibodies obtained using the ELISA technique, but only approximately 58.9\% of the total patients included in the study are confirmed using the anti-Helicobacter pylori Western Blot IgG method. The titer for anti-Helicobacter pylori antibodies identified using the ELISA technique may remain high for a long period of time, up to 6 months, even after the bacterial eradication. The ELISA technique can now be deemed a screening test in adults. Sensitivity and specificity differences were reported for the ELISA technique, using the same commercial kit in different adult populations. The mean antibody titers in infected pediatric patients are much lower compared to mean titers in infected adults.(10)

ESPGHAN does not recommend using serological testing in children neither for initial diagnosis of infection, not for the monitoring of post-therapeutic results. (1)

The Chi-Square independence test statistics showed no statistically significant association between IgA Western Blot and ELISA results, $\chi^{2}(1, \mathrm{~N}=73)=4.2, \mathrm{p}=0.37$, nor between the $\operatorname{IgG}$ Western Blot and ELISA results, $\chi^{2}(1, \mathrm{~N}=73)=2.42, \mathrm{p}=0.65$. The ELISA test is not a specific diagnosis method for Helicobacter pylori infection in children. The humoral immune response to different types of Helicobacter pylori antigens can only be accurately assessed using the Western Blot technique.

A meta-analysis for assessing the accuracy of antibody-based detection tests for diagnosing Helicobacter pylori infection in children included 68 studies, having the following selection criteria: minimum 30 children in the study sample and the use of a gold standard for diagnosing $\mathrm{H}$. pylori infection. The conclusions of this meta-analysis highlighted the fact that Western Blot tests have high performances, with an $89 \%$ specificity and $91 \%$ sensitivity, while ELISA IgG tests had a low sensitivity of $79.2 \%$ and a high specificity of $92.4 \%$. The clinical implications are significant, as a negative ELISA serological test cannot rule out the infection with Helicobacter pylori.(11)

A sample of 73 patients with positive biopsy was selected for the study; 20 patients were tested for Helicobacter pylori stool antigen, obtaining $95 \%$ negative results via immunochromatography. 
Therefore, our results are consistent with international recommendations, which state that the initial diagnosis of infection should not be based on non-invasive methods, namely stool antigen. The test may be recommended for children when endoscopic examination is not possible.(1) There are studies that proved stool antigen could be a useful method for determining pediatric H. pylori infection in developing countries; further research is necessary, including larger patient samples.(12)

Applying Spearman's statistical test for correlating the results obtained via the Helicobacter pylori IgA Western Blot and those obtained via immunochromatography, we obtain the values $r_{s}=-0.096, p$ (2-tailed $)=0.68$, which proves the absence of a statistically significant association.

Applying Spearman's statistical test for correlating the results obtained via the Helicobacter pylori IgG Western Blot and those obtained via immunochromatography, we obtain the values $r_{s}=-0.280, p$ $(2$-tailed $)=0.23$, which proves the absence of a statistically significant association.

We can note that there is no statisticaly significant correlation between the immunochromatography-based determination of stool antigen and the Western Blot technique, proving that the immunochromatography cannot be used as a specific diagnosis method. Authors report that stool antigen detection tests have a lower accuracy when stool samples are loose or watery, because the specific antigens of Helicobacter pylori in the stool samples are diluted. The temperature and time elapsed between stool sample collection and measurements also impact the results. (13)

Another recent study showed that currently available immunochromatography-based tests return less reliable results than those based on anti-Helicobacter pylori antibody detection, the latter also including the Western Blot technique. (14)

\section{Conclusions}

Although non-invasive diagnosis methods are more easily accepted in the pediatric practice by children and parents alike, in the case of $\mathrm{H}$. pylori infections invasive tests have high sensitivity and specificity levels, being recommended by current guidelines. This study supports the utility of the Western Blot method as the preferred method instead of current non-invasive tests; this method has the advantage of avoiding cross-reactivity and enables the detection of low antibody concentrations. In our country, due to limited resources in pediatric endoscopy, the Western Blot technique should be preferred in selected pediatric patients.

\section{References}

1. NICOLA L. JONES, SYBILLE KOLETZKO, et al., Joint ESPGHAN/NASPGHAN Guidelines for the Management of Helicobacter pylori in Children and Adolescents, JPGN, 64, no.6, 2017

2. SIDDALINGAM, RAJINIKANTH \& KUMARAPPAN, CHIDAMBARAM, Trends in Helicobacter Pylori infection, Helicobacter pylori - Current Therapy and Future Therapeutic Strategies, 10.5772/58338, 2014

3. BENJAMIN D., GOLD MD, et al, New Diagnostic Strategies for Detection of Helicobacter pylori Infection in Pediatric Patients, Gastroenterology \& Hepatology, 10, Cap 12, Supliment 7, 2014

4. AMIN TALEBI BEZMIN ABADI, Diagnosis of Helicobacter pylori Using Invasive and Noninvasive Approaches, J Pathog. 2018; 2018: 9064952.

5. REYNDERS MB, MIENDJE DEYI VY, et al., Performance of individual Helicobacter pylori antigens in the immunoblot- based detection of Helicobacter pylori infection. FEMS Immunol. Med. Microbiol, 2012, 64: 352-363

6. HUNT RH, XIAO SD, MEGRAUD F, et al., Helicobacter pylori in developing countries: World Gastroenterology Organisation Global Guideline. J Gastrointestin Liver Dis. 2011; 20:299-304.

7. SHIFERAW G., ABERA D., Magnitude of Helicobacter pylori and associated risk factors among symptomatic patients attending at Jasmin internal medicine and pediatrics specialized private clinic in Addis Ababa city, Ethiopia; BMC Infectious Diseases. 19. 10.1186/s12879-019-3753-5, 2019 
8. ALAM EL-DIN HM, HASHEM AG, et al., Evaluation of noninvasive versus invasive techniques for the diagnosis of Helicobacter pylori infection, Appl Immunohistochem Mol Morphol. 2013 Jul; 21(4):326-33.

9. MONES M. ABU SHADY, HANAN A. FATHY,et al., Comparison of Serum IgG Antibody Test with Gastric Biopsy for the Detection of Helicobacter Pylori Infection among Egyptian Children, 2015 Jun $15 ; 3(2)$ : 303-306.

10. MALFERTHEINER P, MEGRAUD F, O'MORAIN CA, GISBERT JP, et al., Management of Helicobacter pylori infection-the Maastricht V/Florence Consensus Report. Gut. 2017; 66:6-30.

11. LEAL YA, FLORES LL, GARCIA-CORTES LB, CEDILLO-RIVERA R, TORRES J., Antibodybased detection tests for the diagnosis of Helicobacter pylori infection in children: a metaanalysis. PLoS One. 2008; 3(11):e3751.

12. IRANIKHAH A, GHADIR MR, SARKESHIKIAN S, SANEIAN H, HEIARI A, MAHVARI M., Stool antigen tests for the detection of Helicobacter pylori in children. Iran J Pediatr. 2013; 23(2):138142.

13. TADASHI SHIMOYAMA, Stool antigen tests for the management of Helicobacter pylori infection, World J Gastroenterol., 2013; 19(45): 8188-8191

14. KORKMAZ H, KESLI R, KARABAGLI P, TERZI Y.,Comparison of the diagnostic accuracy of five different stool antigen tests for the diagnosis of Helicobacter pylori infection. 2013; 18:384-391.

Manuscript received: 4.12.2019 